\title{
Long-term treatment of pulmonary hypertension with aerosolized iloprost
}

\author{
S. Machherndl*, M. KneussI ${ }^{\#}$, H. Baumgartner*, B. Schneider", V. Petkov", P. Schenk ${ }^{+}$, I.M. Lang*
}

Long-term treatment of pulmonary hypertension with aerosolized iloprost. S. Machherndl, M. Kneussl, H. Baumgartner, B. Schneider, V. Petkov, P. Schenk, I. M. Lang. C) ERS Journals Ltd 2001.

ABSTRACT: Pulmonary arterial hypertension (PAH), defined as elevated pulmonary arterial pressure and pulmonary vascular resistance, is an end-point of a variety of conditions. The only therapy that has been shown to improve both quality of life and survival is intravenous prostacyclin (prostaglandin $\mathbf{I}_{2}\left(\mathbf{P G I} \mathbf{I}_{2}\right)$, epoprostenol).

The effect of long-term aerosolized iloprost (Ilomedin, Schering, Berlin, Germany and Vienna, Austria), a stable prostacyclin analogue and potent vasodilator, on haemodynamics and functional status was investigated in 12 patients with severe pulmonary hypertension. Haemodynamic measurements and vasodilator testing by right heart catheterization were performed prior to and after long-term iloprost inhalation therapy.

Haemodynamic improvement or increased exercise tolerance was not observed in any of the patients. After a mean $\pm S D$ treatment period of $10 \pm 5$ months, mean $\pm S D$ pulmonary vascular resistance had increased from $11 \pm 3$ Wood Units $\left(\mathrm{mmHg} \cdot \mathrm{L}^{-1} \cdot \min \right)$ to $13 \pm 4$ Wood Units, with unchanged arterial oxygen saturation $(92 \pm 4 \%$ versus $91 \pm 4 \%)$. Within the study period, three patients went into right heart failure and had to be placed on intravenous epoprostenol.

The authors conclude that inhaled iloprost in addition to conventional therapy in the presently recommended dose of $100 \mu \mathrm{g} \cdot \mathrm{day}^{-1}$ delivered in 8-10 $2 \mathrm{~h}$ portions, is not an efficient vasodilator therapy in severe pulmonary hypertension. It remains to be shown whether dose increases and/or combination protocols will be effective, or whether inhalation of iloprost may be safe for selected cases of pulmonary hypertension.

Eur Respir J 2001; 17: 8-13.
Depts of *Cardiology, ${ }^{*}$ Pulmonary Medicine, ${ }^{\circ}$ Medical Statistics and ${ }^{+}$Intensive Care Medicine, University of Vienna, Austria.

Correspondence: I.M. Lang

Dept of Internal Medicine II

Division of Cardiology

University of Vienna

Austria

Fax: 14314081148

Keywords: Chronic vasodilator therapy ilomedin

pulmonary hypertension

Received: May 102000

Accepted after revision August 22000

This research was supported in part by Austrian fellowship grants FWFP 10559-MED and P13834-MED (to IML), and by the Ludwig Boltswann Institute for Cardiovascular Research.
Primary pulmonary hypertension (PPH) is an uncommon disease (prevalence 1-2 per million) characterized by increased pulmonary arterial pressure (PAP) and pulmonary vascular resistance (PVR) without any obvious cause [1-4]. The disease has high mortality due to right heart failure, with a median life expectancy of $<3$ yrs after diagnosis [5]. Because early clinical symptoms are nonspecific, the disease is only detected in advanced stages. At this point, it clinically resembles all other forms of pulmonary hypertension (PH) [6].

Because of the finding of a thromboxane and prostacyclin (epoprostenol) metabolite-imbalance [7] and loss of expression of prostacyclin synthase in PH-pulmonary vessels [8], and the observation of thrombotic occlusion of resistance vessels [9], the administration of vasodilators and oral anticoagulation are the main therapeutic strategies. Severe $\mathrm{PH}$ is treated with vasodilators regardless of its aetiology [10, 11], with the exception of chronic thromboembolic pulmonary hypertension (CTEPH) that can be treated by pulmonary thromboendarterectomy (PTE). Supportive medical therapies consist of calcium antagonists, diuretics and oxygen. Selected responders to haemodynamic testing are continued on high-dose calcium channel blockers, but this regimen can improve survival in only a small percentage of adult patients [12].

Patients classified as New York Heart Association (NYHA) class III and IV who fail to respond to conventional therapy, receive long-term epoprostenol (Flolan, GlaxoWellcome, Research Triangle Park, NC, USA) via a permanent central venous catheter. An ambulatory infusion pump is required because of the short half-life of the drug. Continuous infusion of epoprostenol has been practiced for $>10$ yrs [13] and has been shown to improve exercise tolerance and survival rates [14, 15]. However, epoprostenol lacks selectivity for the pulmonary vascular bed. Increased blood flow to low ventilated lung areas may produce hypoxaemia. Catheter infections and sepsis occur in $7-14 \%$ of treated patients. Severe rebound $\mathrm{PH}$ may occur when intravenous epoprostenol is interrupted. Furthermore, high costs of intravenous epoprostenol have led to the search for alternative treatments. Subsequently, prostaglandins have been employed both subcutaneously and as aerosols. Aerosolized prostacyclins were initially used in the intensive care treatment of adult respiratory distress syndrome (ARDS) [16]. It 
has been proposed that aerosolized iloprost (Ilomedin, Schering; i.e. a stable analogue of epoprostenol) causes selective pulmonary vasodilatation, increases cardiac output and improves venous and arterial oxygenation in patients with severe PH [17]. According to recent data by HOEPER et al. [18], long-term treatment with aerosolized iloprost has sustained effects on exercise capacity and pulmonary haemodynamics. The aim of this prospective, open, nonrandomized study was to evaluate the effect of long-term aerosolized iloprost on haemodynamics and exercise tolerance in patients with severe $\mathrm{PH}$.

\section{Materials and methods}

\section{Patients}

The study included 12 patients with precapillary $\mathrm{PH}$ (tables 1 and 2 , mean \pm SD pulmonary capillary wedge pressure (mPCW) $10 \pm 4 \mathrm{mmHg}$ ). The 10 female and two male patients were $48 \pm 17$ yrs old (17-76 yrs) and had a history of PH for $45 \pm 41$ months ( 2 months to 13 years). Two patients had previously undergone surgical closure of a cardiac shunt (patient nos. 6 and 8 ) and had normal or near normal PAP prior to surgery. At the time of initiation of iloprost therapy, no residual shunt was present in these patients. All patients were clinically stable.

Two of the patients with CTEPH had undergone successful PTE within 4 yrs prior to inclusion and had demonstrated re-elevation of pulmonary arterial pressures due to secondary pulmonary vascular changes. For example, in patient no. 5 PVR had been lowered from 1,200 to 480 dynes $\cdot \mathrm{s} \cdot \mathrm{cm}^{-5}$ by successful PTE, but had increased during a subsequent pregnancy. Patient no. 9 had suffered from ARDS as a consequence of aspiration-pneumonia 2 yrs after PTE, and had progressively increased her PVR thereafter. Patient no. 12 suffered from pulmonary arterial hypertension related to collagen vascular disease (CREST: calci- nosis cutis, Raynaud phenomenon, oesophageal dysfunction, sclerodactylia, teleangiectasia).

\section{Study design}

Patients were included February 1997-February 1999. Inhaled iloprost was chosen because the patients were either not felt to be suitable candidates for, or they refused treatment with, intravenous prostacyclin. In more detail: patient no. 3 was considered unable to handle an intravenous infusion pump, patient nos. 2, 6, $7,8,10,11$ and 12 refused intravenous epoprostenol therapy, patient nos. 1, 4, 5 and 9 had known thrombophilic states and had previously suffered from pulmonary thromboemboli associated with intravenous catheters. All patients gave informed consent, came to the hospital every 6 weeks, and had phone contacts every 2 weeks. Equipment was replaced accordingly. In addition to inhaled iloprost, all patients were on standard medical therapy.

\section{Measurements}

Diagnosis was based on clinical history, chest radiograph, spiral computed tomography (CT) with intravenous contrast, high resolution $\mathrm{CT}$, ventilationperfusion lung scan, transthoracic and transoesophageal echocardiography with Doppler, and pulmonary function tests including arterial blood gas analysis at rest and after exercise. Lung volumes were normal in all patients, except patient no. 12 whose one-second forced expiratory volume was 55\% of predicted. Echocardiography and Doppler demonstrated regular mitral, aortic, and tricuspid valve morphology and function in all patients, except for moderate to severe tricuspid regurgitation in patient nos. 1, 3, 4, 5, 6, 7, 9 and 11 . Systolic left ventricular dysfunction, as well as restrictive and constrictive changes were absent.

All patients underwent right heart catheterization at the initiation of therapy and 3-18 months (mean \pm SD

Table 1. - Patient characteristics

\begin{tabular}{|c|c|c|c|c|c|c|c|c|c|}
\hline Patient & Sex & $\begin{array}{l}\text { Age } \\
\text { yrs }\end{array}$ & Diagnosis of $\mathrm{PH}$ & $\begin{array}{l}\text { Time since } \\
\text { diagnosis }\end{array}$ & $\begin{array}{l}\text { Start functional } \\
\text { NYHA class }\end{array}$ & $\begin{array}{l}\text { Walk } \\
\text { test }\end{array}$ & $\begin{array}{l}\text { Therapy duration } \\
\text { months }\end{array}$ & $\begin{array}{c}\text { Iloprost } \\
\text { dose } \\
\mu \mathrm{g} \cdot \text { day }^{-1}\end{array}$ & $\begin{array}{l}\text { Inhalation } \\
\text { regimen } \\
\text { h portions }\end{array}$ \\
\hline 1 & $\mathrm{~F}$ & 60 & СТЕРН* & $2 \mathrm{yrs}$ & II & 450 & 18 & 100 & 3 \\
\hline 2 & $\mathrm{M}$ & 76 & $\mathrm{PPH}^{+}$ & 8 months & III & 295 & 3 & 100 & 2 \\
\hline 3 & $\mathrm{~F}$ & 61 & $\mathrm{PAH}^{\#}$ & 2 yrs & II & $\mathrm{NA}$ & 3 & 100 & 2 \\
\hline 4 & $\mathrm{~F}$ & 52 & СТЕРН & 8 months & III & 400 & 8 & 100 & 4 \\
\hline 5 & $\mathrm{~F}$ & 29 & CTEPH after PTE & 5 yrs & III & 490 & 12 & 150 & 2 \\
\hline 6 & $\mathrm{~F}$ & 33 & $\mathrm{PAH}^{++}$ & 4 yrs & I & 550 & 19 & 100 & 3 \\
\hline 7 & M & 58 & СТЕРН* & $5 \mathrm{yrs}$ & III & 280 & 11 & 150 & 2 \\
\hline 8 & $\mathrm{~F}$ & 17 & $\mathrm{PAH}^{++}$ & $13 \mathrm{yrs}$ & I & 550 & 17 & 100 & 2 \\
\hline 9 & $\mathrm{~F}$ & 50 & CTEPH after PTE & $4 \mathrm{yrs}$ & III & 460 & 4 & 150 & 2 \\
\hline 10 & $\mathrm{~F}$ & 34 & $\mathrm{PAH}^{*, \#}$ & 2 yrs & II & 400 & 11 & 100 & 2 \\
\hline 11 & $\mathrm{~F}$ & 50 & PAH & 2 months & III & 308 & 3 & 100 & 4 \\
\hline 12 & $\mathrm{~F}$ & 56 & PAH & 3 yrs & II & 367 & 11 & 100 & 2 \\
\hline
\end{tabular}

*: Patient not considered to be a surgical candidate; ${ }^{+}$: sporadic; ${ }^{*}$ : pulmonary arterial hypertension related to congenital systemic to pulmonary shunt, secundum atrial septal defect; NA: not available; ${ }^{++}$: pulmonary arterial hypertension related to congenital systemic to pulmonary shunt, ventricular septal defect; PH: pulmonary hypertension; NYHA: New York Heart Association; F: female; M: male; CTEPH: chronic thromboembolic pulmonary hypertension; PPH: primary pulmonary hypertension; PAH: pulmonary arterial hypertension; PTE: pulmonary thromboendarterectomy. 
Table 2. - Patient baseline haemodynamic variables

\begin{tabular}{lcccccccccc}
\hline Patient & $\begin{array}{c}\text { sPAP } \\
\mathrm{mmHg}\end{array}$ & $\begin{array}{c}\text { dPAP } \\
\mathrm{mmHg}\end{array}$ & $\begin{array}{c}\mathrm{mPAP} \\
\mathrm{mmHg}\end{array}$ & $\begin{array}{c}\mathrm{mRAP} \\
\mathrm{mmHg}\end{array}$ & $\begin{array}{c}\mathrm{mPCW} \\
\mathrm{mmHg}\end{array}$ & $\begin{array}{c}\mathrm{CO} \\
\mathrm{L} \cdot \mathrm{min}^{-1}\end{array}$ & $\begin{array}{c}\mathrm{CI} \\
\mathrm{L} \cdot \mathrm{min}^{-1} \cdot \mathrm{m}^{-2}\end{array}$ & $\begin{array}{c}\mathrm{MV}_{\mathrm{sat}} \\
\%\end{array}$ & $\begin{array}{c}S_{\mathrm{a}, \mathrm{O}_{2}} \% \\
\%\end{array}$ & $\begin{array}{c}\mathrm{PVR} \\
\mathrm{dynes} \cdot \mathrm{s} \cdot \mathrm{cm}^{-5}\end{array}$ \\
\hline 1 & 67 & 24 & 41 & 25 & 7 & 3.3 & 2.2 & 64 & 96 & 834 \\
2 & 82 & 22 & 44 & 5 & 12 & 3.2 & 1.9 & 61 & 89 & 800 \\
3 & 93 & 30 & 54 & 8 & 15 & 3.3 & 1.7 & 56 & 89 & 945 \\
4 & 110 & 46 & 72 & 11 & 12 & 3.1 & 2.3 & 57 & 88 & 1548 \\
5 & 76 & 26 & 47 & 7 & 7 & 4.4 & 2.4 & 69 & 94 & 729 \\
6 & 70 & 38 & 52 & 2 & 6 & 5.0 & 3.3 & 71 & 97 & 736 \\
7 & 55 & 34 & 42 & 17 & 15 & 3.8 & 1.7 & 51 & 90 & 573 \\
8 & 85 & 25 & 45 & 9 & 10 & 3.5 & 2.3 & 69 & 98 & 800 \\
9 & 94 & 34 & 58 & 18 & 12 & 3.6 & 1.4 & 45 & 90 & 1022 \\
10 & 84 & 30 & 48 & 7 & 7 & 4.6 & 3.4 & 76 & 96 & 713 \\
11 & 70 & 29 & 42 & 2 & 4 & 3.2 & 1.9 & 71 & 94 & 950 \\
12 & 96 & 30 & 52 & 14 & 14 & 5.1 & 2.5 & 63 & 87 & 596 \\
Mean & $82 \pm$ SD & $31 \pm 6$ & $50 \pm 8$ & $10 \pm 6$ & $10 \pm 4$ & $3.8 \pm 0.7$ & $2.3 \pm 0.6$ & $63 \pm 9$ & $92 \pm 4$ & $854 \pm 257$ \\
\hline
\end{tabular}

sPAP: systolic pulmonary artery pressure; dPAP: diastolic pulmonary artery pressure; mPAP: mean pulmonary artery pressure; mRAP: mean right atrial pressure; mPCW: mean pulmonary capillary wedge pressure; $\mathrm{CO}$ : cardiac output; CI: cardiac index; MVsat: mixed venous oxygen saturation; $\mathrm{Sa}_{\mathrm{a}} \mathrm{O}_{2}$ : arterial oxygen saturation; PVR: pulmonary vascular resistance.

$10 \pm 5$ months) later. For right heart catheterization, a 7 French Swan Ganz catheter (Baxter, Irvine, CA, USA) was inserted from a femoral approach. In selected patients who had undergone inferior vena cava (IVC) filter placement, a jugular approach was chosen (patient nos. 1, 7 and 9). The examination was performed $2 \mathrm{~h}$ after the last iloprost inhalation. Right atrial pressure, pulmonary artery pressure, pulmonary artery wedge pressure and respective oxygen saturations, including the IVC and superior vena cava (SVC), were measured. Mixed venous saturation (MVS) was both measured by assessing pulmonary arterial saturation, and calculated using the formula:

$$
\frac{3 \times \mathrm{SVC}+\mathrm{IVC}}{4}
$$

Cardiac output was assessed both by thermodilution and by the Fick method. Differences between the values obtained by thermodilution and the Fick method ranged from $-1.6-0.8 \mathrm{~L} \cdot \mathrm{min}^{-1}$. With the exception of patient no. 10, where the Fick method was applied, the mean values obtained from both methods were utilized for the statistical calculations. With the catheter in the pulmonary artery, patients subsequently breathed 20 parts per million nitric oxide (NO; Pulmomix, MesserGriesheim, Vienna, Austria) via a continuous positive airway pressure mask (Messer-Griesheim Pulmonoxmini) for $10 \mathrm{~min}$ before a complete haemodynamic measurement was repeated. For this purpose, haemodynamic variables were measured in reverse order upon catheter pull-back. In the first seven patients haemodynamic testing was also carried out using $50 \mu \mathrm{g}$ aerosolized iloprost over $15 \mathrm{~min}$, yielding a haemodynamic response comparable to that under NO application.

\section{Iloprost inhalation}

Patients were instructed in the use of the jet-nebulizer MPV Truma (Gesellschaft für medizintechnische Pro- dukte $\mathrm{mbH}$, München, Germany) which produces a mean particle size of $3 \mu \mathrm{m}$ of aerosolized iloprost at a pressure of 1.2 bar. Initial on-line measurements in the intensive care unit had shown a significant reduction in pulmonary arterial pressure over $45 \mathrm{~min}$ after iloprost inhalation in a series of patients $(n=3$, data not shown). Because the lack of an acute haemodynamic response does not preclude a patient from long-term therapeutic benefit, from intravenous epoprostenol [19], nor from inhaled iloprost [18], nonresponders and responders were treated alike. A daily total dose of $100-150 \mu \mathrm{g}$ iloprost was diluted in $16 \mathrm{~mL} 0.9 \%$ saline and inhaled in 8-10 $2 \mathrm{~h}$ portions. Patients were not awoken at night by intention, but were encouraged to inhale iloprost if they awoke by chance.

\section{Statistical analysis}

Data are presented as means \pm SD. Statistical analysis was performed utilizing a paired t-test and $\mathrm{p}<0.05$ was considered significant.

\section{Results}

\section{Clinical outcomes}

There were few side-effects of the medication. Three patients complained about diarrhoea, three about facial flush, and all patients about occasional cough and nasal congestion. In four patients, platelet counts decreased by $30-50 \%$ during therapy. However, none of the 12 patients showed significant exercise tolerance improvement (as measured by the NYHA functional class; NYHA class 2 before iloprost versus class 3 after iloprost). Six-minute walk test results decreased from $413 \pm 96$ to $224 \pm 192 \mathrm{~m}(\mathrm{p}=0.012)$. Two patients felt better, but showed no improvement in haemodynamic variables both at rest and after administration of NO (patients no. 2 and 6). Patient no. 5 was maintained on iloprost despite an unchanged haemodynamic status at the follow-up examination. Patient no. 1 died from the disease after 18 months of iloprost therapy, 2 weeks 
after the second haemodynamic evaluation. Patient nos. 2, 3, 6, 7, 9, 11 and 12 were taken off iloprost because of worsened haemodynamic data and/or clinical deterioration during therapy, with episodes of liver congestion in patient nos. 2, 3, 7 and 9, and recurrent syncopes in patient nos. 6, 11 and 12. Patient no. 7 was noted to have converted from an NO nonresponder to an NO responder and was taken on a chronic ambulatory NO therapy protocol. Patient nos. 8 and 10 reported to be annoyed by the two-hourly inhalation regimen. Patient no. 8 attempted a suicide and was taken off iloprost thereafter. Patient no. 10 was taken off the drug because of unchanged haemodynamic status and clinical deterioration at the 1-yr follow-up catheter, reporting in a letter to the referring physician that suicide had been attempted. Patient nos. 3,4 and 9 were immediately started on epoprostenol infusions and were listed for lung transplantation, with patient no. 9 undergoing a successful double lung transplant after 6 months of epoprostenol therapy. Patient nos. 2, 6, 10, 11 and 12 still refused epoprostenol treatment and were taken on an investigational subcutaneous prostacyclin formulation. Patient no. 8 has remained without vasodilator therapy.

\section{Haemodynamic measurements}

Baseline haemodynamic measurements prior to chronic inhalation therapy are shown in table 2. In all patients PAP and PVR were elevated (mean PAP $50 \pm 8 \mathrm{mmHg}$, PVR $854 \pm 257$ dynes $\cdot \mathrm{s} \cdot \mathrm{cm}^{-5}$ ). Cardiac output $(\mathrm{CO})$ was $3.8 \pm 0.7 \mathrm{~L} \cdot \mathrm{min}^{-1}$, cardiac index (CI) was $2.3 \pm 0.6 \mathrm{~L} \cdot \mathrm{min}^{-1} \cdot \mathrm{m}^{-2}$. Systemic vascular resistance (SVR) was $1,988 \pm 289$ dynes $\cdot \mathrm{s} \cdot \mathrm{cm}^{-5}$. After long-term inhalation therapy no improvement in haemodynamic data could be observed (table 3 ). In contrast, systolic PAP increased to $93 \pm 15 \mathrm{mmHg}(\mathrm{p}<0.05)$, diastolic PAP increased to $38 \pm 8 \mathrm{mmHg}(\mathrm{p}<0.03)$, mean PAP increased to $57 \pm 9 \mathrm{mmHg}(\mathrm{p}=0.02)$, SVR decreased to $1810 \pm 423$ dynes $\cdot \mathrm{s}^{\cdot} \mathrm{cm}^{-5}(\mathrm{p}=0.3)$, and PVR increased to

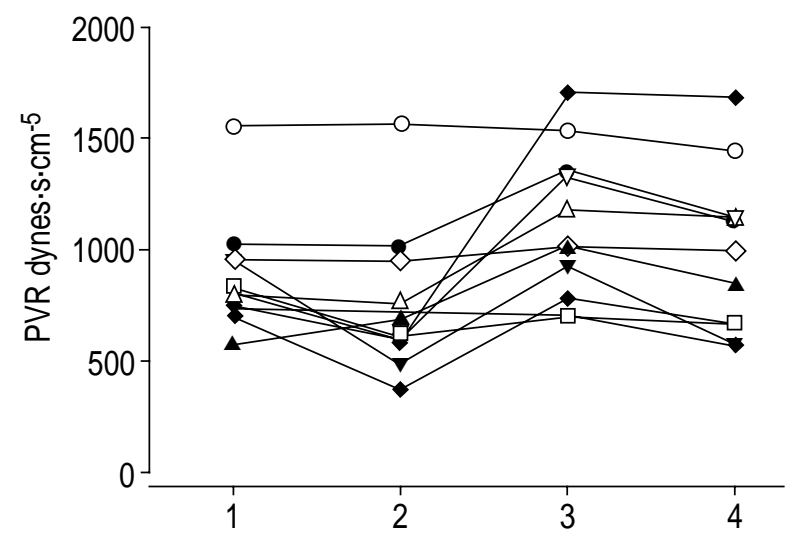

Fig. 1. - Pulmonary vascular resistance: 1) at baseline; 2) upon challenge with 20 parts per million nitric oxide over 10 min to test acute pulmonary vasoreactivity during baseline cardiac catheterization; 3) after long-term therapy with inhaled iloprost; and 4) at the second nitric oxide challenge. Symbols represent values of individual patients.
$1088 \pm 327$ dynes $\cdot \mathrm{s} \cdot \mathrm{cm}^{-5}(\mathrm{p}<0.02$, fig. 1). MVS decreased to $54 \pm 13 \%(\mathrm{p}<0.03)$.

\section{Haemodynamic testing}

Prior to iloprost therapy, only two patients were classified as responders, defined as a decrease of PVR and mean PAP $\geqslant 20 \%$ (fig. 1). After long-term inhalation of iloprost, no significant restoration of a vasodilator response could be observed. One patient converted from a nonresponder to a responder despite overall deterioration of clinical and haemodynamic values (patient no. 7). A previous responder was a nonresponder at the second haemodynamic evaluation (patient no. 10, fig. 1).

\section{Discussion}

The present findings demonstrate that chronic aerosolized iloprost did not improve clinical and haemodynamic parameters in 12 patients. In contrast, NYHA functional class and functional capacity deteriorated, which disagrees with the expectations raised by short-term assessments [20]. Furthermore, PAP, PVR and MVS were significantly worse after chronic iloprost inhalation, possibly reflecting the natural progression of pulmonary vascular disease [3]. The acute haemodynamic effect of inhaled iloprost and the observed side-effects support the concept that the inhalation device provided an efficient tool to deliver the drug.

The present investigation is limited by several factors. Firstly, the number of patients is small. Secondly, the open, uncontrolled nature of the present study does not allow firm conclusions to be drawn about a possible lack of effectiveness of inhaled iloprost. Thirdly, a fixed-dose regimen was chosen without dose adjustments that may be required in the individual patient. Fourthly, patient compliance is a possible confounding factor that could not be controlled for. In addition, there exist numerous, very recently published nonrandomized reports on the great short-term and longterm therapeutic efficacy of this prostacyclin derivative $[18,20-24]$. In comparison with the very recently published paper by HOEPER et al. [18], the patients in the present study were older, suffered from more, longstanding disease and only $16 \%$ compared with $50 \%$ were haemodynamic responders. Taken together, the patients of HOEPER et al. [18] represent a group of patients with a more favorable prognosis. Five of these patients (the $\geqslant 50 \%$ responders) may have also been considered for oral high-dose calcium antagonists [12]. However, it is often the older patients feeling insecure about sterile techniques that physicians elect for the iloprost inhalation treatment. Therefore, the authors believe that their data are important.

Several other valuable issues are addressed in the current study. Firstly, the choice of patients was based on their suitability and consent for epoprostenol therapy, thus resulting in random allocations to the iloprost regimen. Secondly, all patients suffered from $\mathrm{PH}$ in the absence of left ventricular dysfunction or 
Table 3. - Patient haemodynamic variables after long-term iloprost therapy

\begin{tabular}{|c|c|c|c|c|c|c|c|c|c|c|}
\hline Patient & $\begin{array}{l}\text { sPAP } \\
\mathrm{mmHG}\end{array}$ & $\begin{array}{l}\text { dPAP } \\
\text { mmHG }\end{array}$ & $\begin{array}{c}\text { mPAP } \\
\text { mmHG }\end{array}$ & $\begin{array}{l}\text { mRAP } \\
\text { mmHg }\end{array}$ & $\begin{array}{l}\mathrm{mPCW} \\
\mathrm{mmHG}\end{array}$ & $\underset{\mathrm{L} \cdot \mathrm{min}^{-1}}{\mathrm{CO}}$ & $\underset{\mathrm{L} \cdot \mathrm{min}^{-1} \cdot \mathrm{m}^{2}}{\mathrm{CI}}$ & $\underset{\%}{M V_{\text {sat }}}$ & $\underset{\%}{\mathrm{Sa}_{\%}, \mathrm{O}_{2}}$ & $\begin{array}{c}\text { PVR } \\
\text { dynes } \cdot \mathrm{s} \cdot \mathrm{cm}^{-5}\end{array}$ \\
\hline 1 & 91 & 25 & 50 & 22 & 15 & 3.9 & 2.5 & 52 & 97 & 712 \\
\hline 2 & 67 & 29 & 42 & 8 & 8 & 2.3 & 1.4 & 60 & 92 & 1183 \\
\hline 3 & 85 & 45 & 62 & 8 & 12 & 4.0 & 2.2 & 40 & 90 & 1000 \\
\hline 4 & 117 & 41 & 71 & 9 & 10 & 3.2 & 2.3 & 68 & 90 & 1525 \\
\hline 5 & 85 & 35 & 45 & 6 & 10 & 4.0 & 2.1 & 42 & 95 & 700 \\
\hline 6 & 99 & 40 & 62 & 17 & 11 & 2.4 & 1.6 & 48 & 94 & 1700 \\
\hline 7 & 85 & 35 & 50 & 28 & 12 & 3.6 & 1.7 & 34 & 84 & 844 \\
\hline 8 & 118 & 58 & 74 & 10 & 5 & 4.2 & 2.5 & 67 & 97 & 1314 \\
\hline 9 & 100 & 38 & 56 & 17 & 7 & 2.9 & 1.4 & 43 & 88 & 1352 \\
\hline 10 & 73 & 37 & 48 & 6 & 9 & 4.0 & 3.0 & 70 & 92 & 780 \\
\hline 11 & 92 & 36 & 58 & 5 & 6 & 4.5 & 2.6 & 67 & 94 & 924 \\
\hline 12 & 102 & 34 & 60 & 8 & 14 & 3.6 & 1.7 & 59 & 92 & 1022 \\
\hline Mean \pm SD & $93 \pm 15$ & $38 \pm 8$ & $57 \pm 9$ & $12 \pm 7$ & $10 \pm 4$ & $3.6 \pm 0.7$ & $2.1 \pm 0.5$ & $54 \pm 13$ & $91 \pm 4$ & $1088 \pm 327$ \\
\hline
\end{tabular}

SPAP: systolic pulmonary artery pressure; dPAP: diastolic pulmonary artery pressure; mPAP: mean pulmonary artery pressure; mRAP: mean right atrial pressure; mPCW: mean pulmonary capillary wedge pressure; $\mathrm{CO}$ : cardiac output; CI: cardiac index; MVsat: mixed venous oxygen saturation; $\mathrm{Sa}_{\mathrm{a}} \mathrm{O}_{2}$ : arterial oxygen saturation; PVR: pulmonary vascular resistance.

structural lung disease, thus yielding a homogenous patient population. The authors are currently investigating the degree of secondary vascular changes in CTEPH in addition to the thromboembolic "fixed obstructive" lesions. The data show that pulmonary vasoreactivity to $\mathrm{NO}$ is preserved in $25 \%$ of cases (unpublished observation). In agreement with these findings, preliminary applications of vasodilator drugs have been promising in secondary PH [25]. Thirdly, although 17 patients were actively treated with inhaled iloprost within the study period with very similar clinical outcomes as those patients in the study, only patients undergoing two catheter evaluations were included in the report. Therefore, the present study delivers novel as yet unpublished information on the haemodynamic status of 12 patients with PAH and CTEPH on chronic inhaled iloprost. In contrast to the most recent study of OLSCHEWSKI [21], patients were not in overt and progressive right heart failure at the initiation of therapy, and patients maintained iloprost therapy over at least three months. Although inhaled iloprost demonstrates a marked acute vasodilator effect, it did not alter cardiac output in the present study $\left(3.8 \pm 0.71 \cdot \mathrm{min}^{-1}\right.$ at baseline versus $3.6 \pm 0.71 \cdot \mathrm{min}^{-1}$ after $10 \pm 5$ months of iloprost therapy). In contrast, intravenous epoprostenol was observed to increase cardiac output $3.76-6.291 \cdot \mathrm{min}^{-1}$ after 12 months [19]. The beneficial effect of long-term epoprostenol remains largely unknown. Whether the effect on cardiac output is a critical factor that determines survival rates will be shown by future studies.

The authors conclude that inhaled iloprost, in addition to conventional medical therapy, and delivered in $8-102 \mathrm{~h}$ portions in the presently recommended dose of $100-150 \mu \mathrm{g} \cdot \mathrm{day}^{-1}$, is not an efficient long-term therapy in patients with a clinical profile similar to that of the study population. In addition, psychological stress resulting from the need for two-hourly inhalations, is particularly threatening young female patients. It remains to be shown whether iloprost dose increases and/or combination protocols, e.g. inhaled iloprost plus phosphodiesterase inhibitors, will be more effective.

\section{References}

1. Anderson EG, Simon G, Reid L. Primary and thromboembolic pulmonary hypertension: a quantitative pathological study. J Pathol 1973; 110: 273-293.

2. Bjornsson J, Edwards WD. Primary pulmonary hypertension: A histopathologic study of 80 cases. Mayo Clin Proc 1985; 60: 16-25.

3. Rubin LJ. Primary pulmonary hypertension. Chest 1993; 104: 236-250.

4. Higenbottam T, Weitzenblum E. Pulmonary hypertension: Mechanisms and treatment. Eur Respir J 1996; 8: 1991-1992.

5. D'Alonzo GE, Barst RJ, Ayres SM, et al. Survival in patients with primary pulmonary hypertension. Results from a national prospective registry. Ann Intern Med 1991; 115: 343-349.

6. Primary Pulmonary Hypertension: Executive Summary from the World Symposium - Primary Pulmonary Hypertension 1998. In: World Symposium - Primary Pulmonary Hypertension 1998; Evian, France: Available from the World Health Organization via the Internet (http://www.who.int/ncd/cvd/pph.html).

7. Christman $\mathrm{BW}, \mathrm{McPherson} \mathrm{CD}$, Newmann $\mathrm{JH}$, et al. An imbalance between the excretion of thromboxane and prostacyclin metabolites in pulmonary hypertension. $N$ Engl J Med 1992; 327: 70-75.

8. Giaid A, Saleh D. Reduced expression of endothelial nitric oxide synthase in the lungs of patients with pulmonary hypertension. N Engl J Med 1995; 333: 214-221.

9. Wagenvoort CA, Wagenvoort N. Primary pulmonary hypertension: a pathologic study of the lung vessels in 156 clinically diagnosed cases. Circulation 1970; 42: 1163-1184.

10. Barst RJ. Long-term prostacyclin reduces pulmonary vascular resistance in severe primary pulmonary hypertension. Clin Exp Rheumatol 1998; 16: 253-254.

11. Badesch DB, Zamora M, Fullerton D, et al. Pulmonary capillaritis: a possible histologic form of acute pulmonary allograft rejection. $J$ Heart Lung Transplant 1998; 17: 415-422.

12. Rich S, Kaufmann K, Levy PS. The effect of high 
doses of calcium-channel blockers on survival in primary pulmonary hypertension. $N$ Engl J Med 1992; 327: 76-81.

13. Higenbottam $\mathrm{T}$, Wheeldon $\mathrm{D}$, Wells $\mathrm{F}$, Wallwork $\mathrm{J}$. Long-term treatment of primary pulmonary hypertension with continuous intravenous epoprostenol (prostacyclin). Lancet 1984; 1: 1046-1047.

14. Barst RJ, Rubin LJ, McGoon MD, Caldwell EJ, Long WA, Levy S. Survival in primary pulmonary hypertension with long-term continuous intravenous prostacyclin. Ann Intern Med 1994; 121: 409-415.

15. Barst R, Rubin LJ, Long W, et al. A comparison of continuous intravenous epoprostenol (prostacyclin) with conventional therapy for primary pulmonary hypertension. N Engl J Med 1996; 334: 296-301.

16. Walmrath D, Schneider T, Pilch J, Grimminger F, Seeger W. Aerosolised prostacyclin in adult respiratory distress syndrome. Lancet 1993; 342: 961-962.

17. Olschewski $\mathrm{H}$, Walmrath $\mathrm{D}$, Schermuly $\mathrm{R}$, et al. Aerosolized prostacyclin and iloprost in severe pulmonary hypertension. Ann Intern Med 1996; 124: 820824.

18. Hoeper MM, Schwarze M, Ehlerding S, et al. Longterm treatment of primary pulmonary hypertension with aerosolized iloprost, a prostacyclin analogue. $N$ Engl J Med 2000; 342: 1866-1870.

19. McLaughlin W, Genthner DE, Panella MM, Rich S. Reduction of pulmonary vascular resistance with long term epoprostenol (prostacyclin) therapy in primary pulmonary hypertension. $N$ Engl J Med 1998; 338: 273-277.

20. Wensel R, Opitz CF, Ewert R, Bruch L, Kleber FX. Effects of iloprost inhalation on exercise capacity and ventilatory efficiency in patients with primary pulmonary hypertension. Circulation 2000; 101: 2388-2392.

21. Olschewski H, Ghofrani HA, Schmehl T, et al. Inhaled iloprost to treat severe pulmonary hypertension. An uncontrolled trial. German PPH Study Group. Ann Intern Med 2000; 132: 435-443.

22. Olschewski H, Ghofrani HA, Walmrath D, Temmesfeld-Wollbruck B, Grimminger F, Seeger W. Recovery from circulatory shock in severe primary pulmonary hypertension (PPH) with aerosolization of iloprost. Int Care Med 1998; 24: 631-634.

23. Olschewski H, Walmrath D, Schermuly R, Ghofrani HA, Grimminger F, Seeger W. Prostacyclin and iloprost in aerosol form in severe pulmonary hypertension. Pneumologie 1998; 52: 3-7.

24. Hoeper MM, Olschewski H, Ghofrani HA, et al. A comparison of the acute haemodynamic effects of inhaled nitric oxide and aerosolized iloprost in primary pulmonary hypertension. German PPH study group. $J$ Am Coll Cardiol 2000; 35: 176-182.

25. McLaughlin W, Genthner DE, Panella MM, Hess DM, Rich S. Compassionate use of continuous prostacyclin in the management of secondary pulmonary hypertension: a case series. Ann Intern Med 1999; 130: 740-743. 